\title{
On the relationship between spiritual care competence of nurses working in Shafa Hospital with their quality of working life
}

\author{
Tayeb Shariatipour ${ }^{1}$, NasrinElahi ${ }^{2 *}$, Abdolali Shariati ${ }^{3}$ and Mohammad Hosein Haghighizadeh ${ }^{4}$ \\ ${ }^{1}$ Student - Faculty of Nursing and Midwifery, Jundishapur University of Medical Sciences, Ahvaz Iran \\ ${ }^{2}$ Assistant Professor - Nursing Care Research Center in Chronic Diseases Faculty of Nursing and Midwifery, \\ Jundishapur University of Medical Sciences, Ahvaz Iran \\ ${ }^{3}$ Nursing Instructor, Faculty Member of Nursing and Midwifery Faculty, Jundishapur University of Medical \\ Sciences, Ahvaz Iran \\ ${ }^{4}$ Faculty Member of Department of Statistics and Epidemiology, School of Public Health, Jundishapur University of \\ Medical Sciences, Ahvaz Iran
}

\begin{abstract}
Spiritual care is one of the basic principles of nursing practice that addresses the spiritual needs of patients. According to the World Health Organization, this dimension has been neglected. This study was conducted in 2016 to evaluate the correlation between spiritual care Competences of nurses working in Shafa hospital of Ahvaz with their quality of working life.The research type was descriptive and co relational. Population of study includes all nurses working in the Shafa hospital of Ahvaz. One hundred nurses who had the criteria for the study were selected by convenience sampling. These nurses have answered the demographic questionnaire, the spiritual care Competence questionnaire and the quality of working life questionnaire. Data were analyzed using SPSS22 software and descriptive statistics and inferential statistics such as Pearson correlation and multiple regressions.The results showed that there is a significant positive correlation between the spiritual care with quality of working life of nurses $(\mathrm{p}=0.02)$, being professional $(p=0.02)$, personal support $(p=0.001)$, referral to specialists $(p=0.02)$, attitude to patient's religious spirits $(p=0.02)$ and relationships $(\mathrm{p}=0.01)$. The results of regression analysis indicated that the variable of personal support can significantly anticipate the quality of working life of nurses. $(\mathrm{p}=0.001)$. Based on the results of this study, the relationship between spiritual well-being and quality of work life in nurses, especially the role of later personal support as a predictor of quality of working life, and its positive impact on improving patient care services and, consequently, patient's satisfaction of care, it is recommended that relevant authorities in macro planning to motivate and improve the quality of life of personnel on the merits of spiritual care and special attention support.
\end{abstract}

KEY WORDS: SPIRTTUAL CARE COMPETENCE, QUALITY OF WORKING LIFE, NURSES

\section{ARTICLE INFORMATION:}

*Corresponding Author: nasrinelahi137@gmail.com,

Elahi-n@ajums.ac.ir

Received $27^{\text {th }}$ Dec, 2017

Accepted after revision $21^{\text {st }}$ March, 2018

BBRC Print ISSN: 0974-6455

Online ISSN: 2321-4007

Ains: Thomson Reuters ISI ESC / Clarivate Analytics USA and

Crossref Indexed Journal

NAAS Journal Score 2017: 4.38 SJIF 2017: 4.196

$\odot$ A Society of Science and Nature Publication, Bhopal India 2018. All rights reserved.

Online Contents Available at: http//www.bbrc.in/

DOI: $10.21786 / \mathrm{bbrc} / 11.1 / 15$ 


\section{INTRODUCTION}

One of the most important dimensions of the human being's existence is spirituality, which includes a set of values, attitudes and hopes that connect one to a superior being and binds to health, goodness, and healing (Ross, et al. (2014). Today, the role of spirituality in promoting the health of the patient has been more concerned and helping to meet the spiritual needs of patients and their families is considered as the main element of clinical care (McSherry and Cash. (2004 Usha Devi 2015).

Despite the fact that spiritual care is an essential component of nursing practice, and any health care system that seeks to provide comprehensive care, it considers spiritual care as an essential part of care (Chan et al. 2006). But the World Health Organization emphasizes that this aspect of care to meetthe needs of the patients' spiritual needs has been neglected (Chan et al. (2006, Mazaheri, et al., 2008). While Mazaheri and colleagues found in their study that nurses had a positive attitude toward spirituality and spiritual care, (Mazaheri,et al., 2008.) On the other hand, Strong et al. noted that, although $87 \%$ of nurses believed that they had to pay attention to the spiritual needs of patients, only $42 \%$ of them thought that these measures would be done in their parts (Strang, Strang, and Ternestedt,2002Colichi et al., 2017).

This is while spirituality and spiritual care of nurses help them in their duties, especially in dealing with patients (Gholamali et al., 2007), because spiritual care has a significant contribution in achieving preservation and promotion of health, preventing the disease, and eliminating ill health and discomfort (Farahani et al. (2005).Therefore, meeting the spiritual needs of patients should be an integral part of nursing interventions (Cavendish et al., (2003).

In this regard, Florence Nightingaleemphasizes: "The nurse plays an important role in improving the patient's health by taking into account the spiritual and psychological aspects of the patient" (Macrae, (2001). The American Nursing Association also considers the spiritual dimension as a center of nursing attention in expressing clinical practice standards, (ANA,2007). Therefore, comprehensive nursing care can be considered as body care, mind and soul, as an essential and vital part of caregiver and is a unique aspect of care, and a nurse who claims to provide comprehensive care should have the Competence of spiritual care (Newman et al., (1991). In other words, this competence can affect the provision of optimal services and quality of care.

Spiritual care is especially important for cancer patients, since cancer diagnosis and treatment is associated with a high degree of physical and psychological disturbances (Stein, et al., 2008). Apart from the stage of cancer, patients experience a great deal of fear and are uncertain about the side effects and benefits of treatments and how these factors affect their future lives (Kazer et al., 2013,Borneman, et al., 2014). Therefore, in the long run, cancer and its treatment can reduce the well-being of patients not only in the physical and psychological aspects, but also in the spiritual dimension (Conway, 2010). Therefore, specialists in this field should be equipped in the spiritual domain and related issues to meet such needs of cancer patients.

Studies have also emphasized the positive impact of attention to spiritual issues in improving the quality of care and thus the health of patients. For example, in a study by Rahnema et al. in 2014, with the purpose of designing a spiritual care model in the rehabilitation of cancer patients found that identifying and addressing the spiritual needs of patients through a systematic approach, development of knowledge and sensitivity of nurses to the spiritual needs of patients, spiritual deserving and empowerment of nurses, team performance enhancement and family support to provide spiritual care for patients during rehabilitation are essential (Rahnama et al., 2014). In addition, the positive effects of religious worship on the desire for life, the feeling of goodness and happiness, the reduction of anxiety and tension and the strengthening of other therapeutic processes are documented in most cultures and religions, (Dilshod 2016, Colichi et al., 2017).

The results of these studies indicate that spirituality is one of the factors affecting the quality of working life (Shojaee and Khazaee 2011 and Usha Devi 2015). Despite the fact that employee satisfaction surveys have long been of concern to organizations providing health services, and the managers of these organizations have used the results to solve organizational problems, today, a new concept of job satisfaction, entitled "quality of workinglife" is intended for managers, (Dalagas 2016). Quality of working life is a comprehensive and inclusive plan that is aimed at promoting the satisfaction of staff and is necessary for each organization to attract and retain employees (Bredle, et al. (2011). This program has a number of specific features, such as meeting standards in work, giving people equal opportunity to hire and provide fair payrolls for employees, amenities, health and safety considerations, participation in decision making, management practices, diversity and richness of businesses (Donald et al., 2011) and Beaudoin, and Hassles, 2003). In relation to nurses, due to their job nature, quality of working life is influenced by four factors of social, executive, managerial and cultural conditions that the occurrence of problems and deficiencies in this field causes job dissatisfaction and, as a result, psychological exhaustion and job loss (Taghavi 2004). 
There are few studies on the relationship between the quality of working life and the Competence of spiritual care among nurses, although the findings are still consistent. The results of van der Walt \&tKlerk (2014).), Ming Chia (2012) Asaroodi and Akbari (2011); Jafari and Khodayari (2012) and Nejad, and Ghalavandi 2012) have shown that there is a significant relationship between the subscales of spiritual care with quality of working life. For example, in a study conducted by Sharpe (2016)entitled the role of religion and ethics in balancing work and life of employees, he concluded that those who have high levels of spirituality and morals comparing those who have lower spiritual levelscan better balance between their work and life.The balance between work and life is one of the subscales of variable of the quality of working life (Sharpe 2016). Also, it was found that structured education based on spirituality increases nurses' quality of working life (Sydkavvsy and 2015).

Regarding the fact that spiritual care, more than the technical aspects of care, will lead to patient satisfaction as well as special attention of Ministry of Health and Medical Education to the category of spirituality, which is considered to be the required duties of treatment groups, the limitedresearches in this field in the field of nursing and work researcher's experience in the care of cancer patients, the researchers attempted to determine the relationship between the spiritual carecompetence of nurses working in the Shafa hospital with the quality of their working life in 2016.

\section{MATERIAL AND METHODS}

The research method is descriptive-analytic and a correlationtype (registration code: B-9542). The statistical population consisted of all nurses working in different parts of ShafaHospital of Ahvaz University of Medical Sciences (which is a special wardfor cancer) in 2016. The total number of nurses was 120 and 104 of them had inclusion criteria (voluntary consent, being employed in one of the wards of the Shafa hospital and having at least 6 months of work experience), 100 of them were selected by census method . Using ethical considerations (code of ethics: IRAJUMS.REC.1395559), 120 questionnaires were submitted to the nurses to be completed, of which 100 questionnaires were completedwith no defect completed.

\section{RESEARCH TOOLS}

A) Spiritual Care Competence Questionnaire: This questionnaire was designed by Van Leone et al. in 2009. The questionnaire consists of six dimensions related to nursing Competence in providing spiritual care as follows:
"Spiritual Care"; related to assessment and implementation of this dimension refers to the ability to identify spiritual needs and planning for spiritual care (6 questions). "Professionalism and improvement of the quality of spiritual care" includes the part of nurses' activities aimed at ensuring the quality of care and extending policies in the field of spiritual care (6 questions). "Personal support and counseling with patient ", which is the heart of spiritual care, is the actual provision and evaluation of face-to-face care for the patient and his relatives (6 questions). Referral to specialists is related to other areas of health care, and the religious advisor with the expert in providing religious counseling is clearly its point of view (3 questions). "Attitude towards the religious beliefs of the patient", in which the individual factors related to the provision of spiritual care are categorized (4 questions). "Communication" is the contact between the nurse and the patient ( 2 questions). Students were asked to identify their level of Competence for providing spiritual care on a five point Likert scale (Koren et al. (2009),Khalaj et al (2103)) in their research found that the Cronbach's alpha coefficient for the whole tool is 0.77 and for subcategories is between 0.65 and 0.85 . All questions had a significant intra-questions correlation. The results of the test-retest showed the stability of the questionnaire and its subcategories. The exploratory factor analysis with Varimaxrotation, created 6 factorswithEigengreater than one, describing $63.18 \%$ of the variance. The subcategories showed good homogeneity, with mean intra-correlation of questions greater than 0.35 and the reliability coefficient of the test-retest test. The confirmatory factor analysis showed acceptable fitness for the 6-factor model.

B) Quality of working life questionnaire: This questionnaire contains 39 items in the form of a 5-point Likert scale, which a score of 1-5 is assigned for each item, so that the score of 5 is considered for totally agree and the score of 1 for totally disagree. This scale has four subscales in assessing the nurses' quality of working life, including: 1. Working life-home life; 2. working plan; 3. working background; 4. working world. The first subscale is working -home life or the interface between working and home life of nurse. Since nurses are mostly women, this dimension shows the role of mother (child care), daughter (caring for elderly parents), and wife (family needs) of nurses in contrast to the working environment. Theworking plan subscale is the combination of nursing work and describes the real work that nurses do. The working background subscale includes functional environments in which the nurses work and examines the impact of the work environment on the patient and nurse.

This dimension represents the human and environmental factors related to the field of work, in other 
words, the conditions and opportunities for training to improve the performance of work and the interpersonal relationships of colleagues. Obviously, improving the quality of the field of work (working background) provides the conditions necessary to increase the effectiveness of the staff. The working world subscale reflects the social and occupational contexts and the social feedback of the job position in the individual in the form of job satisfaction. This dimension has a social impact on the performance of nurses. The internal reliability of the questionnaire has been reported by Brooks et al. in various dimensions ranging from 0.56 to 0.85 . Khani and his colleagues reported the reliability of the above questionnaire in the research between 0.75 and 0.93.

The collected data were analyzed using SPSS software version 22 by use of descriptive (mean and standard deviation) and inferential (Pearson correlation coefficient and multiple regression with simultaneous method) statistics.

\section{RESULTS AND DISCUSSION}

Data analysis showed that $24 \%$ of subjects were male and $76 \%$ were female. Also, the mean age of the experimental group was $36.65 \pm 7.49$. Most of the research subjects (73\%) were married. In terms of education, the majority of subjects were undergraduates (48\%) and graduate students (48\%) and the rest (4\%) were associate degree students. Finally, the highest working experience was 19 years and the least 2 years. The mean and standard deviation of spiritual careCompetence and quality of working life subscales are presented in Table 1.

The Pearson correlation coefficient was used to measure the relationship between spiritual careCompetenceand quality of working life, as presented in Table 2. As can be seen, the correlation coefficients between spiritual care Competence (evaluation and implementation of spiritual care, professionalism, personal support, referral to specialists, external attitude and communication) and quality of working life was $0.22,0.22,0.41,0.22,0.22$ and 0.23 , respectively, which are statistically significant.

In order to predict the quality of working life, simultaneous multiple regression analysis was used, as shown in Table 3.

Table 3 shows that, among the six subscales of spiritual care, only personal support provides a significant prediction of the quality of working life score. That is, if the personal support variable increases a standard deviation, the quality of working life score will be increased equal to 0.35 (beta value) ofstandard deviation. The remaining variables do not predict quality of working life significantly.

The results of the above table show that the modified value of $\mathrm{R}$ in the predictive model predicts $16 \%$ of the variance in the quality of working life score.

The aim of this study was to investigate the relationship between spiritual careCompetenceof nurses working in Shafa hospital and their quality of working life in 2016. The results of this study showed that there is a positive and significant relationship between spiritual careCompetencesubscales (assessment and implementation of spiritual care, professionalism, personal support, referral to specialists, external attitude and communication) with quality of working life. This means that with the increase in spiritual care, quality of working life increases, and with its decline, the quality of working life decreases. This finding is consistentwith the results of the researches conducted byseveral others and shows that paying attention to spirituality in the sphere of standard health care will increase the quality of working life.

For example, in a research in 2015, Usha Devi showed that components of spiritual leadership, including altruistic love, hope, faith, contact, membership, organizational commitment, and quality of working life positively affect each other. Sharp's (2016) study also showed that the existence of high levels of spirituality and ethics among employees leads to a balance between work and life as one of the indicators of the quality of working life. In

\begin{tabular}{|c|c|c|c|}
\hline Variable & Number & Mean & $\begin{array}{l}\text { Standard } \\
\text { deviation }\end{array}$ \\
\hline Evaluation and implementation of spiritual care & 100 & 20.16 & 4.39 \\
\hline Professionalism & 100 & 21.93 & 3.89 \\
\hline Personal support & 100 & 20.22 & 4.60 \\
\hline Referral & 100 & 11.15 & 2.35 \\
\hline external Attitude & 100 & 14.68 & 2.88 \\
\hline Communication & 100 & 6.96 & 1.90 \\
\hline Overall Score of Spiritual Care Competence & 100 & 67.03 & 13.10 \\
\hline Quality of working life & 100 & 95.10 & 13.16 \\
\hline
\end{tabular}


Table 2. Pearson correlations of spiritual care Competencesubscales with quality of working life

\begin{tabular}{|l|l|l|}
\hline \multirow{2}{*}{ Variable } & \multicolumn{2}{|c|}{ Quality of working life } \\
\cline { 2 - 3 } & Correlation coefficient & Significance level \\
\hline evaluation and implementation of spiritual care & 0.22 & 0.02 \\
\hline professionalism & 0.22 & 0.02 \\
\hline personal support & 0.41 & 0.001 \\
\hline referral to specialists & 0.22 & 0.02 \\
\hline external attitude & 0.22 & 0.02 \\
\hline Communication & 0.23 & 0.02 \\
\hline
\end{tabular}

Table 3. Simultaneous multivariate regression analysis to predict the quality of working life through the variable levels of spiritual care Competence in nurses

\begin{tabular}{|l|l|l|l|l|l|}
\hline Predictive variables & B & $\begin{array}{l}\text { Standard } \\
\text { error }\end{array}$ & Beta & $\begin{array}{l}\text { T } \\
\text { value }\end{array}$ & $\begin{array}{l}\text { Significance } \\
\text { level }\end{array}$ \\
\hline Fixed number & 28.13 & 8.96 & & 3.13 & 0.002 \\
\hline personal support & 1.007 & 0.30 & 0.35 & 3.30 & 0.001 \\
\hline evaluation and implementation of spiritual care & 0.43 & 0.29 & 0.14 & 1.50 & 0.13 \\
\hline professionalism & 0.29 & 0.37 & 0.088 & 0.79 & 0.43 \\
\hline referral to specialists & 0.25 & 0.67 & 0.045 & 0.37 & 0.70 \\
\hline external attitude & 0.24 & 0.56 & 0.05 & 0.44 & 0.66 \\
\hline Communication & 0.34 & 0.72 & 0.04 & 0.46 & 0.64 \\
\hline
\end{tabular}

fact, people who have a high understanding of morals and spiritual principles, try to comply with the professional principles in dealing with the needs of their family members or in dealing with hospital patients. Also, conflicts between family life and working life of nurses are sometimes considered as an important source for their performance. Nurses who experience severe conflicts have a lower quality of working life and this relationship has been studied in various researches. The spiritual wellbeing and the high spiritual potential in them will enable them to manage and balance the stresses from the sources of family resources and work resources.

Regression analysis to determine the predictive value of quality of working life from the six subscales of spiritual careCompetence showed that among the six subscales of spiritual care Competence, merely the personal support had a positive and significant prediction of quality of working life variance in such a way that by increasing one unit in the personal support score, a difference of 0.35 in the standard deviation of the quality of working life of the nurses is obtained. Seyed-kavousi

Table 4. Summary of the results of the predictive power of the spiritual careCompetencefrom variable of quality of working life innurses

\begin{tabular}{|l|l|l|l|}
\hline Model & R & R-square & R \\
\hline 1 & 0.46 & 0.21 & 0.16 \\
\hline
\end{tabular}

and Nasr-Esfahani, in 2015, conducted a studyaimed at influencing the components of spiritual leadership on the quality of working life of nurses.

The findings showed that the levels of productivity with a significance level of 0.064 , work outlook of 0.045 and faithfulness of 0.033 had the highest effect on quality of working life, and the remaining variables of spiritual leadership had a relatively weak linear relationship, but no significant level, with quality of working life (Koren et al 2009).

The findings of this study, consistent with the present study, have shown that structured education based on spirituality increases nurses' quality of work.In explaining the findings of the research, it can be said that the spirituality in the workplace and the familiarity of nurses with the principles of spiritual care will make nurses look better at the patients. For example, Chia states in his research that the principles related to the spirituality and familiarity of nurses ultimately correlate with the observance of their professional ethics.

In explaining the relationship between professional ethics of spirituality, they argued that nurses, with the understanding of the patient's needs, responsibility, and a strong relationship between medical staff and patients, lead to a climate of high responsibility and commitment that are indicators of the quality of working life of nurses. Bell 2006 in their research have shown that nurses who are religiously healthy tend to recognize the 
spiritual needs of patients. Nurses may not be able to communicate with the patient due to lack of familiarity with the study of religious needs and lack of knowledge and skills in providing religious care, and sometimes the patient may think that the nurse is in fact intending to interfere in his religious affairs, while if a nurse is familiar with the way the patient's religious assessment is considered and is part of his/her career, as well as the ability to communicate with the patient appropriately, he/she will be able to identify the spiritual needs of the patient and provide the same as other physical and mental needs.Thus, considering the importance of the spiritual dimension in nursing for providing spiritual care to the patient along with physical and mental care and the necessity of practicing this skill in nurses, they ultimately improve their services to patients and increase their quality of work. .

\section{LIMITATIONS}

The psychological and fatigue effects of completing the questionnaires and the focus of the study on nurses, which limit the generalization of the findings to other team members, are among the limitations of this study.

\section{CONCLUSION}

In this research, the relationship between spiritual care and its subscales with quality of working life was investigated. Findings showed that there is a positive and significant relationship between the level of spiritual care, professionalism, personal support, referral to specialists, attitude towards the patient and the level of communication of nurses with quality of working life, and even the quality of life score can be predicted through the spiritual care score. In general, factors such as understanding patients and their needs, observing ethics, responsibility and professionalism in performing nursing duties are considered as spiritual care features that have a very effective role in increasing the quality of working life of nurses. Considering the importance of paying attention to spiritual needs, especially in patients with incurable diseases such as cancer, education and promotion of spiritual care in the treatment team, especially nurses, will be accompanied by the well-being and physical and mental health of the patients. On the other hand, reducing job burnout and psychological distress leads to increased spiritual well-being and quality of working life for nurses.

\section{CONFLICT OF INTEREST}

The authors have no conflict in writing this article.

\section{ACKNOWLEDGMENTS}

We thank the relevant authorities and nurses participating in this research.

\section{REFERENCES}

Asarudi. A, Golafshani. A, and Akaberi. A. (2011). Relationship between spiritual health and quality of life in nurses. Journal of North Khorasan University of Medical Sciences, 3(4). (Persian)

American Nurses Association, (A.N.A). (2007). Corrections nursing: Scope and standards of practice. Amer Nurses Assn.

Beaudoin, L.E. and L. Edgar, Hassles. (2003). Their importance to nurses' quality of work life. Nursing Economics, 21(3), 106.

Bell, R.S. (2006). Spirituality and job satisfaction: A correlational study among nurses. Argosy University.

Borneman, T., Irish, T., Sidhu, R., Koczywas, M., \&t Cristea, M. (2014). Death awareness, feelings of uncertainty, and hope in advanced lung cancer patients: can they coexist. International journal of palliative nursing, 20(6), 271.

Bredle, J.M., et al. (2011). Spiritual well-being as a component of health-related quality of life: the functional assessment of chronic illness therapy-spiritual well-being scale (FACIT-Sp). Religions, 2(1): p. 77-94.

Brooks, B. A. Anderson, M. A. (2005).Defining Quality of Nursing Work Life. Nursing Economics, 23(6), 319-326.

Cavendish R, Konecny L, Mitzeliotis C, Russo D. (2003). Spiritual care activities of nurses using nursing interventions classification (NIC) labels. International Journal of NursingKnowledge. 214(4):113.

Chan M, Chung L, Lee A, Wong W, Lee G, Lau C, et al. (2006). Investigating spiritual care perceptions and practice patterns in Hong Kong nurses: results of a cluster analysis. Nurse Educ Today. 26(2), 139-50.

Chia,M C. (2012). The influence of workplace spirituality on motivations for earnings management: A study in Taiwans hospitality industry. Journal of Hospitality Management and Tourism, 3(1), 1-11.

Colichi, R.M.B., et al. (2017). Interactions between Quality of Life at Work and Family: Integrative Review. International Archives of Medicine, 9(1).

Conway, J. (2010). Integrating spiritual care as part of comprehensive cancer treatment. Oncology Nurse Adviser, 24-27.

Dalagas, L.S., 2016 Effective managers and leaders in nursing, Tehran: Basharee.

Dilshod A. 2016., The influence of religion in maintaining mental balance and hope in the elderly. Comprehensive database of health,. Education and Culture 3(11): p. 136-145.

Donald K., Harvey F. and D.B. Roy. (2011). Experimental Approach to Development (change management). Tehran: State Management Training Center

Farahani M. Hui R. Nia M, et al. (2005). Spiritual health and nursing students about their views of spirituality and spiritual 
care of patients. Iran Journal of Nursing. 18(44): 7-13. [persion]

GholamaliLavasani M, Keivanzadeh M, Arjmand N. (2007). Spritualty, job stress, organizational commitment and job satisfaction among nurses in Tehran. Compelmentry Psychology. 2(3), 61-73 (Persian).

Hsiao, Y.-C., H.-Y. Chiang, and L.-Y. Chien. (2010). An exploration of the status of spiritual health among nursing students in Taiwan. Nurse Education Today, 30(5), 386-392.

Khani A, Jaafarpour M, Dyrekvandmogadam A. Quality of nursing work life. Journal of Clinical and Diagnostic Research.2008; 2(6):1169-1174.

Kazer, M. W., Bailey Jr, D. E., Chipman, J., Psutka, S. P., Hardy, J., Hembroff, L., ... \& Sanda, M. G. (2013). Uncertainty and perception of danger among patients undergoing treatment for prostate cancer. BJU international, 111(3b).

Khalaj M, Pakpour Haji Agha A, and MohammadiZeidi I. (2103) "Validity and Reliability of Nursing Students Competence Questionnaire in Providing Spiritual Care" The Journal of Qazvin University of Medical Sciences. 64-70 (Persian)

Shojaee P and Khazaee. F, 2011 Relationship between quality of work life with the spiritual leadership of University College of Medical Sciences. . Journal of Medical Sciences, 16(4): p. 68-62. (Persian)

Koren, ME, Czurylo, K, Epsom R, Gattuso M, Stark B, Zastrow P, et al. (2009). Nurses' work environment and spirituality: a descriptive study. International Journal of Caring Science. 2(3):118-124.

Macrae, J.A. (2001). Nursing as a Spiritual Practice: A Contemporary Application of Florence. Springer Publishing Company.

Maleki. M.R, et al. (2012). The relationship between spiritual leadership and quality of work life martyr Hashemi Nejad Hospital in Tehran. Health Information Management, 8(8). (Persian)

Mazaheri, M., Fallahi, KHM, \&t Sadat, MS. (2008). [Nurses' attitudes to spirituality and spiritual care]. Payesh Journal. 8 (1), 7-31) Persian.

McSherry, W. \& K. Cash. (2004). The language of spirituality: an emerging taxonomy. International journal of nursing studies. 41(2), 151-161.
Newman, M.A., A.M. Sime, and S.A. (1991). Corcoran-Perry, The focus of the discipline of nursing. Advances in Nursing Science, 14(1): p. 1-6.

Rahnama, M., et al.,2014 Model of spiritual care in rehabilitation for patients with cancer. Surgical nursing, 2014. 3(2): p. 70-61.(Persian)

Ross, L., et al. (2014). Student nurses perceptions of spirituality and Competence in delivering spiritual care: a European pilot study. Nurse Education Today, 34(5), 697-702.

Sandrick, K. (2003). Putting the emphasis on employees. Trustee: the journal for hospital governing boards. 56(1), 6 .

Sharpe, M. (2016). Investigating How Religiosity, Ethics, and Other Factors Relate to Future Accounting and Business Professionals' Views on Work-Life Balance.

Stein, K. D., Syrjala, K. L., \&t Andrykowski, M. A. (2008). Physical and psychological long-term and late effects of cancer. Cancer, 112(S11), 2577-2592.

Strang, S., P. Strang, and B. Ternestedt, 2002 Spiritual needs as defined by Swedish nursing staff. Journal of clinical nursing, 11(1): p. 48-57.

Sydkavvsy E (2015), Investigate the impact of spiritual leadership on quality of work life for nurses using structural equation. Journal of Clinical Nursing 19(2): p. 147-154.

Taghavi, p. (2004). Quality of working life and its impact on nurses' performance. 19, ed. 8., Tehran: Homa Health. (Persian).

Usha Devi. N, Spiritual Leadership and its Relationship with Quality of Work Life and Organizational Performance - An Exploratory Study . . Finance and Banking (EAR15 Swiss Conference), 2015. 3(54).

Van der Walt, F. and J.J. (2014). de Klerk, Workplace spirituality and job satisfaction. International Review of Psychiatry, 26(3), 379-389.

Yassaminezhad. Parisa, Golmohammadian. M, and Youssefi. N. (2012). The relationship between spiritual health and job involvement among faculty members. Journal of Occupational and Organizational Consulting, 3(8). (Persian). 